\title{
A Questionnaire Based Study Regarding the Knowledge, Attitude and Practice of Self- Medication Among Second Year Undergraduate Medical Students
}

\author{
Rajanish Kumar Sankdia1, Mehul Agrawal'*, Parabathina Bindu Rekha1, Nitin Kothari² \\ ${ }^{1}$ Department of Pharmacology, Chirayu Medical College \& Hospital, Bhopal, Madhya Pradesh. INDIA. \\ ${ }^{2}$ Department of Pharmacology, Pacific Medical College, Udaipur, Rajasthan. INDIA.
}

\begin{abstract}
Background: Self-medication is becoming very common in our routine life which is an unhealthy and risky practice. Present study was done to determine the knowledge, attitude and practice of self-medication among second year undergraduate medical students of a private medical college in Bhopal, Madhya Pradesh. Material and methods: A pre-validated questionnaire was prepared and distributed among the students. Data was collected and analysed using Microsoft Excel and the results expressed as counts and percentages. Results: Total 139 students participated in the study voluntarily and most common reason for taking Self-medication was that there was no need to visit the doctor for minor illness. In maximum students, source of information of the drugs used for Self-medication was previous prescription and source of the drugs was medical store. Only 39\% MBBS students accepted the fact, that they always visited a qualified practitioner whenever they fell ill. Most of the students took Self-medication for headache followed by cough, cold and fever. Out of total 139 students, most of the students took NSAIDS as Self-medication followed by lozenges. Conclusion: This study showed that students of second year MBBS after studying pharmacology became more aware about the drugs and hence do not hesitate in taking Self-medication which is a wrong practice. Key words: Self-medication, Questionnaire, Second Year MBBS, Knowledge, Attitude, Practice.
\end{abstract}

Citation: Sankdia RK, Agrawal M, Rekha PB, Kothari N. A Questionnaire Based Study Regarding the Knowledge, Attitude and Practice of Self-Medication Among Second Year Undergraduate Medical Students. Int J Pharmacol and Clin Sci.2017;6(1):01-05.

\section{INTRODUCTION}

Self-medication is defined as the use of medication by a patient on his own initiative or on the advice of a Pharmacist or a lay person instead of consulting a medical practitioner (WHO guidelines, 2000)..$^{[1]}$ It has been observed that medical and paramedical students are commonly involved in the practice of self-medication, without complete knowledge about the therapy they are taking. ${ }^{[2]}$

Non-prescription drugs amongst youth, especially in students are being misused due to exposure to media and advertisements. It has become a serious ailment raising the concern of incorrect diagnosis and drug reaction as well. Being future medical practitioners, Self-medication has a special impact in medical students. Prevalence of Self-medication was found to vary in medical students of different countries in earlier studies. ${ }^{[3,4,5,6,7]}$ undertaken to ascertain the Self-medication practice among medical students. Since majority of the studies were conducted in countries other than India, pattern of Self-medication

Received : 07-03-2017 Revised : 28-03-2017;

Accepted : 30-03-2017

*Correspondence : Dr. Mehul Agrawal,

Assistant Professor, Dept of Pharmacology,

Chirayu Medical College \& Hospital, Bhopal, Madhya

Pradesh. INDIA.

Phone no: 09827584900

E-mail: drmehulagrawal@yahoo.co.in

Conflict of interest: Nil ; Source of support : Nil

Copyright: ${ }^{\odot} 2017$ Journal. All rights reserved.

DOI : 10.5530/ijpcs.6.1.1 
practices in our country remained uncharted. With this in mind, the present study was planned to determine the pattern of Self-medication practices, to find out the common ailments and common drugs used, reasons for Self-medication along with assessing relationship between the level of medical education and the Selfmedication practices among medical undergraduates.

On one hand, students become more and more cautious in practising self medication, knowing that irrational and inappropriate usage of them might be more harmful than useful, so they, even in situations of minor illnesses prefer taking any medication only after consultation from a qualified practitioner. On the other hand, they may become confident, and in most cases, overconfident, regarding their "bookish" knowledge and may start implementing self care. They may either become successful in this attempt boosting up their confidence levels, hence encouraging them for its continued use or even over-use, or may suffer such setbacks leading to a detrimental health or a diseased state. However, it is also recognized that self-medication must be accompanied by appropriate health information. ${ }^{[6]}$

\section{MATERIALS AND METHODS}

An anonymous questionnaire-based study in all the medical students of 2 nd year MBBS attending theory classes in the department of Pharmacology in a private medical college, of central India, was conducted after getting permission from ethics committee of the college.

Students of all ages and both sexes were included in the study. A brief description of the nature of the study and the procedure of completing the questionnaire was explained to students taking part in the study. Questionnaire was self developed and pre validated consisting of twelve closed ended questions. The survey was descriptive and data was summarised as counts and percentages. Microsoft word and excel programs were used for analysis of data.

\section{RESULTS}

Total 139 students participated in the study voluntarily, out of them 57 (41\%) were males and 82 (59\%) were females. Mean age in years was 20.25; range was from 18 to 27 years.Out of 139 students total $123(88.5 \%)$ students took Self-medication and the rest $16(11.5 \%)$ students have not taken Self-medication ever till now.

\section{Knowledge}

Most common reasons for taking Self-medication were that there was no need to visit the doctor for minor illness (71\%), it was time saving (58\%), Self-medication provided quick relief (55\%), and there was ease and convenience in taking Self-medication (44\%). (Table 1)

The most common reasons for not taking Selfmedication were that there was lack of knowledge about medicines $(75 \%)$, risk of adverse effects $(75 \%)$, risk of using wrong drugs (69\%) and risk of misdiagnosing (69\%). (Table 2).

In 97 (70\%) students source of information of the drugs used for Self-medication was previous prescription.In $78(56 \%)$ students source of the drugs used for Selfmedication was medical store.

\section{Attitude}

In our study we found that out of 139 students only 54 (39\%) MBBS students accepted the fact, that they always visited a qualified practitionerwhenever they fell ill, while $65(47 \%)$ students said that they sometimes visited and 4(3\%) students visited only rarely.

\section{Practice}

Out of total 139, students most of the students $n=109$ (78\%) took Self-medication for headache followed by cough and cold $n=98(70 \%)$ and fever $n=90(65 \%)$. (Table 3).

Out of total 139 students, most of the students $n=115$

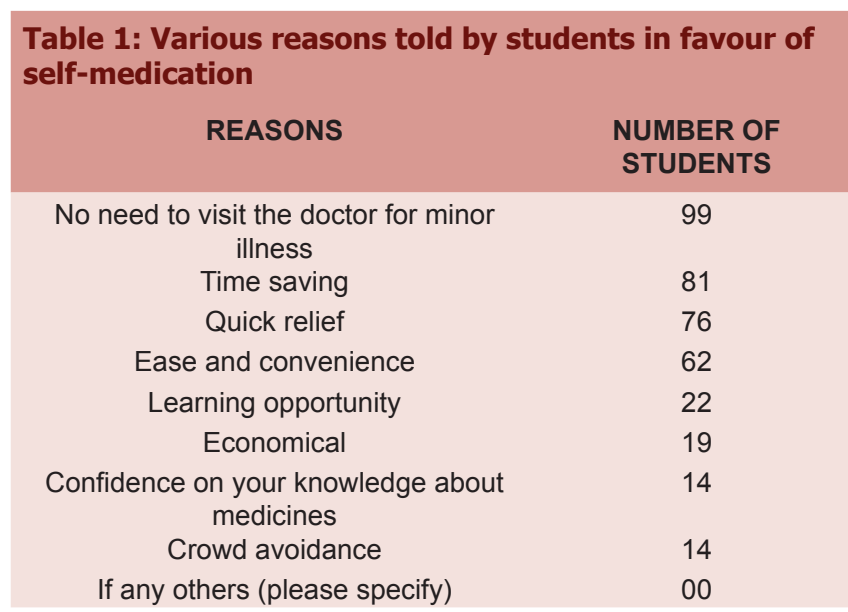




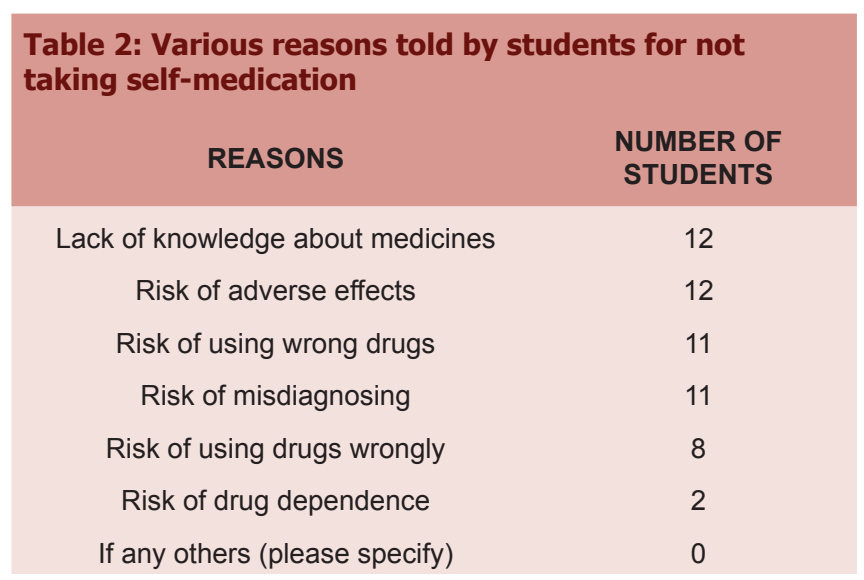

$\begin{aligned} & \text { Table 4: Different drugs used for self-medication in our } \\
& \text { study }\end{aligned}$
\begin{tabular}{cc} 
DRUG & $\begin{array}{c}\text { NUMBER OF } \\
\text { STUDENTS }\end{array}$ \\
\hline Analgesics & 115 \\
Lozenges & 75 \\
Multivitamins & 66 \\
Decongestants & 66 \\
Antimicrobials & 57 \\
Antispasmodics & 45
\end{tabular}

$(83 \%)$ took analgesics as Self-medication followed by lozenges $\mathrm{n}=75$ (54\%) (Table 4).

Out of 139 students, total $123(88.5 \%)$ students took Self-medication and the rest $16(11.5 \%)$ students have not taken Self-medication ever till now. Among those students who took Self-medication 75 students sometimes practised while 47 students rarely practised and 4 students always practised self medication.

\section{DISCUSSION}

In our study, we found that female students were more interested in taking Self-medication as compared to male students; this may be due to the fact that the female students are more hesitant to go to the hospital or outpatient department for minor illness. Similar findings were there in the study done by Thadani et al. ${ }^{[8]}$

Out of 139 students total 123 (88.5\%) students took self medication, which is supported by the studies done elsewhere reported $76 \%$ in Karachi, ${ }^{[3]} 94.1 \%$ in Slovenia, ${ }^{[4]} 76.9 \%$ in Bahrain. ${ }^{[6]}$

In our study, most of the students who took

\begin{tabular}{|c|c|}
\hline INDICATION & $\begin{array}{l}\text { NUMBER OF } \\
\text { STUDENTS }\end{array}$ \\
\hline Headache & 109 \\
\hline Cough, cold, sore throat & 98 \\
\hline Fever & 90 \\
\hline Stomach ache & 50 \\
\hline Diarrhoea & 41 \\
\hline Vomiting & 39 \\
\hline Menstrual symptoms & 31 \\
\hline Ocular symptoms & 5 \\
\hline
\end{tabular}

Self-medication gave some reasons in favour that there was no need to visit the doctor for minor illness $(71 \%)$, it was time saving (58\%), andSelf-medication provided quick relief $(55 \%)$ and reasons given by rest of the students for not taking Self-medication were that there was lack of knowledge about medicines (75\%), risk of adverse effects $(75 \%)$ and risk of using wrong drugs (69\%). Similar findings were there in the study done by James et al. ${ }^{[6]}$

In our study, we found that source of information of the drugs used for Self-medication was previous prescription, this may be due to the fact that they had visited the doctor for the same illness previously and do not found it necessary to again visit the doctor for the similar complaints.

We also found that major source of the drugs used for Self-medication was medical store; this may be due to ease and convenience, similar results were found in the study done by Klemenc et al. ${ }^{[4]}$

We found that most of the students took Self-medication for problem of headache, this may be due to the strain on eyes while studying and lack of sleep for which they had to take analgesics, most of the times which was self administered.Similar findings were there in study done by Zafar et al..$^{[3]}$ andJames et al. ${ }^{[6]}$

Analgesics were the most common group of drugs used for Self-medication in our study; similar findings were there in the study done by James et al.$^{[6]}$ and Thadani et al. ${ }^{[8]}$

\section{CONCLUSION}

Thepractice of Self-medication on the basis of 
incomplete knowledge should be avoided and medical students who are themselves future healthcare providers of this nation, should be educated about the disadvantages of taking drugs without proper advice of a qualified doctor.

\section{REFERENCES}

1. Porteous $T$, Bond $C$, Hannaford $P$, Sinclair H.How and why are non-prescription analgesics used in Scotland? FamPract 2005;22(1):78-85.

2. Montgomery AJ, Bradley C, Rochfort A, Panagopoulou E. A review of self-medication in physicians and medical students. Occup Med (Lond). 2011;61(7):490-7. doi: 10.1093/occmed/kqr098. Epub 2011 Jul 4. [PubMed: 21727179]

3. Zafar SN, Syed R, Waqar S, Zubairi AJ, Vaqar T, Shaikh $M$, et al. Self-medication amongst University Students of Karachi: Prevalence, Knowledge and Attitudes. J Pak Med Assoc. 2008;58(4):214-7.

\section{QUESTIONNAIRE}

This questionnaire is designed to help us understand your preferences regarding knowledge, attitude and practice of self medication. Participation depends on your willingness. No personal information should be written on the paper (name, roll number).

Please answer legibly and add checkmark in front of the appropriate answers.

\section{QUESTIONS:}

1) Initials:
2) Age (yrs):
3) Sex:

4) Whether taken Self-medication or not? Yes/ No

5) If yes, whether practised self medication
a) Always
b) sometimes
c) rarely

6) If yes, whether visited to a qualified medical practitioner
a) Always
b) sometimes
c) rarely

7) If yes, then which of the following was the source of information of the drugs used for self medication?
4. Klemenc-Ketis Z, Hladnik Z, Kersnik J. Self-medication among healthcare and non-healthcare students at University of Ljubljana, Slovenia. Med PrincPract. 2010;19(5):395-401. doi: 10.1159/000316380. Epub 2010 Jul 14. [PubMed: 20639665]

5. Sontakke SD, Bajait CS, Pimpalkhute SA, Jaiswal KM, Jaiswal SR. Comparative study of evaluation of self-medication practices in first and third year medical students.Int $\mathrm{J}$ Biol Med Res. 2011;2(2):561-4.

6. James H, Handu SS, Al Khaja KA, Otoom S, Sequeria RP. Evaluation of the knowledge, attitude, and practice of selfmedication among first-year medical students.Med Princ Pract. 2006;15(4):270-5. [PubMed: 16763393]

7. Abay SM, Amelo W. Assessment of self-medication practices among medical, pharmacy, and health science students in Gondhar University, Ethiopia. J Young Pharm. 2010;2(3):306-10. doi: 10.4103/0975-1483.66798.[PMCID: PMC2964771] [PubMed: 21042491]

8. Thadani S, Salman MT, Ahmad A. Knowledge, Attitude and Practice of Self-medication Among Second Year Undergraduate Medical Students. J Rational Pharmacother Res. 2013;1(3):131-4.
a) Classroom teaching
c) advertisement
b) textbook
d) previous

prescription

8) If yes, then what was the source of the drugs used for self-medication?
a) Medical store
b) home

c) doctor parents

9) According to you which of the following were the reasons in favour of self medication?

\begin{tabular}{|l|l|}
\hline No need to visit the doctor for minor illness & \\
\hline Quick relief & \\
\hline Time saving & \\
\hline Confidence on your knowledge about medicines & \\
\hline Economical & \\
\hline Ease and convenience & \\
\hline Learning opportunity & \\
\hline Crowd avoidance & \\
\hline If any others (please specify) & \\
\hline
\end{tabular}

10) According to you what were the indications for self medication?

\begin{tabular}{|l|l|}
\hline Headache & \\
\hline Fever & \\
\hline Cough, cold, sore throat & \\
\hline Stomach ache & \\
\hline
\end{tabular}




\begin{tabular}{|l|l|}
\hline Menstrual symptoms & \\
\hline Vomiting & \\
\hline Diarrhoea & \\
\hline Ocular symptoms & \\
\hline If any others (please specify) & \\
\hline
\end{tabular}

11) According to you which of the following drugs were used for self medication?

\begin{tabular}{|l|l|}
\hline Analgesics & \\
\hline Antimicrobials & \\
\hline Multivitamins & \\
\hline Antispasmodics & \\
\hline Decongestants & \\
\hline Lozenges & \\
\hline If any others (please specify) & \\
\hline
\end{tabular}

12) According to you which of the following were the reasons for not taking self medication?

\begin{tabular}{|l|l|}
\hline Lack of knowledge about medicines & \\
\hline Risk of adverse effects & \\
\hline Risk of using wrong drugs & \\
\hline Risk of misdiagnosing & \\
\hline Risk of drug dependence & \\
\hline Risk of using drugs wrongly & \\
\hline If any others (please specify) & \\
\hline
\end{tabular}

